\title{
Neuroaxonal Dystrophy in a mule: first case reported
}

[Distrofia neuroaxonal em muar: primeiro relato de caso]

\author{
L.F.A. Toledo ${ }^{1}$, H.L. Jerdy ${ }^{2}$, P.C.A.R. Silva ${ }^{1}$, E.C.Q. Carvalho ${ }^{2}$, D.A.B. Lessa ${ }^{1}$ \\ ${ }^{1}$ Universidade Federal Fluminense - Niterói, RJ \\ ${ }^{2}$ Universidade Estadual do Norte Fluminense "Darcy Ribeiro" - Campos dos Goitacazes, RJ
}

\begin{abstract}
A 12-month-old mule (sterile hybrid equine species) presented unspecific neurological changes (symmetric ataxia, dysmetria, conscious proprioceptive deficit and weakness). Due to poor prognosis and to the fact that a sibling from the previous generation exhibited similar clinical signs that were not definitively diagnosed, the animal was euthanized. Diagnosis of neuroaxonal dystrophy was confirmed by anatomohistopathological analysis. This is the first clinical case of neuronal dystrophy in a mule reported in the world. The clinical and histopathological characteristics of this disease were very similar to those reported for several equine breeds. Therefore, the disease should also be considered in the diagnosis of neurological conditions in mules and donkeys.
\end{abstract}

Keywords: ataxia, degenerative myeloencephalopathy, donkey, neurology

\section{RESUMO}

Relata-se o caso de uma mula de 12 meses que apresentou alterações neurológicas inespecíficas (ataxia simétrica, dismetria, déficit proprioceptivo consciente e fraqueza). Devido ao mau prognóstico e ao fato de um irmão da geração anterior apresentar sinais clínicos similares sem diagnóstico conclusivo, o animal foi eutanasiado. O diagnóstico de distrofia neuroaxonal foi confirmado por análise anátomohistopatológica. Esse é o primeiro caso clínico de distrofia neuroaxonal em muar relatado no mundo. As características clínicas e histopatológicas dessa doença foram muito semelhantes às relatadas em várias raças de equinos. Portanto, a doença também deve ser considerada no diagnóstico de condições neurológicas em muares e asininos.

Palavras-chave: ataxia, mieloencefalopatia degenerativa, asinino, neurologia

\section{INTRODUCTION}

Neuroaxonal dystrophy (NAD) in humans is described as an unspecific disorder and may occur concomitantly with several genetic diseases, vitamin deficiency and aging (Gordon, 2002). The condition has been diagnosed in sheep, cats, dogs, horses (Beech and Haskins, 1987) and is characterized by bilateral symmetric neuroaxonal degeneration of selected nuclei and axonal processes in the central nervous system (CNS) (Finno et al., 2011). The lesions observed include eosinophilic spheroids in the nuclei of the brainstem, and significant axonal degeneration does not occur in the spinal cord (McGavin and Zachary, 2007).

Equine degenerative myeloencephalopathy (EDM) is a degenerative, symmetric, and progressive neuronal disease described in young horses (Mayhew et al., 1978). EDM is considered the most severe form of NAD, and the two diseases are clinically indistinguishable (Finno, 2012). EDM and NAD are, therefore, variants of the same disease. Axonal degeneration in the spinal cord is the most noticeable lesion observed in EDM, occurring bilaterally and possibly affecting all funicles (McGavin and Zachary, 2007) .

Recebido em 30 de outubro de 2017

Aceito em 5 de dezembro de 2018

E-mail: lfatoledo@id.uff.br 
The animals affected with the complex NAD/EDM (Finno, 2012) exhibit neurological abnormalities that include symmetric ataxia, dysmetria, conscious proprioceptive deficit and weakness. These signs usually emerge during the first year of life (Beech and Haskins, 1987; Baumgärtner et al., 1990). Evidence has shown that NAD/EDM has a strong hereditary component (Baumgärtner et al., 1990). The progression and severity of the disease have also been associated with vitamin E deficiency, though so far its etiology has not been clarified (Finno et al., 2011).

Despite the clinical reports of NAD/EDM in several horse breeds, including Mongolian, Standardbreds, Morgans, Paso Fino, Haflingers, Appaloosa, Paint, Norwegian Fjord, Tennessee Walking Horses, a Welsh Pony, Thoroughbreds, Arabians, Quarter, a Pony of the Americas, as well as Lusitano, (Mayhew et al., 1978; Beech and Haskins, 1987; Baumgärtner et al., 1990; Finno et al., 2011; Finno, 2012) no case report of the disease complex has been described in mules, which are sterile hybrid equine species. The clinical and anatomohisthopathological aspects of the disease are very similar across breeds, and these occurrences may also have the same etiology (Finno, 2012). The objective of this study was to describe the clinical and anatomohistological findings in a mule with a diagnosis of NAD/EDM in Brazil.

\section{CASE REPORT}

A 12-month-old female mule born from a mixedbreed mare and a Pega donkey in a farm in the state of Rio de Janeiro, Brazil was examined. Clinical record revealed that a sibling (same mare and stallion) from a previous generation presented similar clinical signs and was euthanized without clinical examination or necropsy. The animal presented incoordination, erratic rambling and apathy starting 3 months before examination. At presentation the animal was bright, alert and responsive, with marked proprioceptive ataxia in pelvic limbs. Locomotion and posture were classified as grade 3, according to Mayhew and Reed classification system (Reed, 1998).

There was poor postural reaction to conscious proprioception in pelvic limbs. Segmental reflexes regarding muscle tone were decreased in pelvic limbs and increased in thoracic limbs. Perineal reflex, tail tonus, panniculus, and skin reflexes were decreased. There were no abnormalities in cranial nerves. Epaxial muscle palpation showed discrete hyperalgesia in the lumbar region and discrete hypoalgesia in the sacral region. Nociceptive reaction in the cervical region of the vertebral column was normal, however, discrete hypoalgesia was observed in pelvic limbs. Urination and defecation were normal. Clinical signs indicated that the probable lesion site was the T3-L3 region, with upper motor neuron affection and no cauda equina syndrome.

Blood samples were collected from the jugular vein and cerebrospinal fluid was collected by puncture of the cisterna magna. CBC and serum biochemistry assays (urea, creatinine, alkaline phosphatase and gamma GT) were within normal limits. Glycemia level was $90 \mathrm{mg} / \mathrm{dL}$ and glycose level in the cerebrospinal fluid was $80 \mathrm{mg} / \mathrm{dL}$. Cytological evaluation of the cerebrospinal fluid showed $40 \%$ segmented cells, $40 \%$ lymphocytes and $19 \%$ monocytes.

Due to clinical record and poor prognosis, a decision was made for euthanasia. An anatomopathological evaluation was performed. At gross inspection there were no changes in thoracic and abdominal cavities or viscera, also brain, spinal cord, nerve roots, and vertebral column appeared to be normal. Brain, spinal cord, fragments of thoracic and abdominal viscera, gluteus muscles, tongue, and diaphragm were collected for histopathological analysis. The fragments were fixed by immersion in $10 \%$ buffered formalin.

Microscopically, lesions of the central nervous system were symmetric. There were cellular bodies with dissolution of Nissl bodies, central chromatolysis, vacuolization and strong neuronal eosinophilia related with necrotic neurons. Vacuoles, proliferated microglia, demyelination characterized by oval to round eosinophilic formations, microgliosis and axonal spheroids were identified on white matter. There was demyelination, neuronal necrosis and axonal spheroids on neocortex, corpus calossum and ammon's horn. Mesencephalon, metencephalon and oblong medulla showed extensive chromatolysis, dissolution of Nissl bodies, vacuolization and neuronal necrosis, as well as 
demyelination, abundant axonal spheroids (10/400x) and multifocal microgliosis. (Figure 1 and 2)

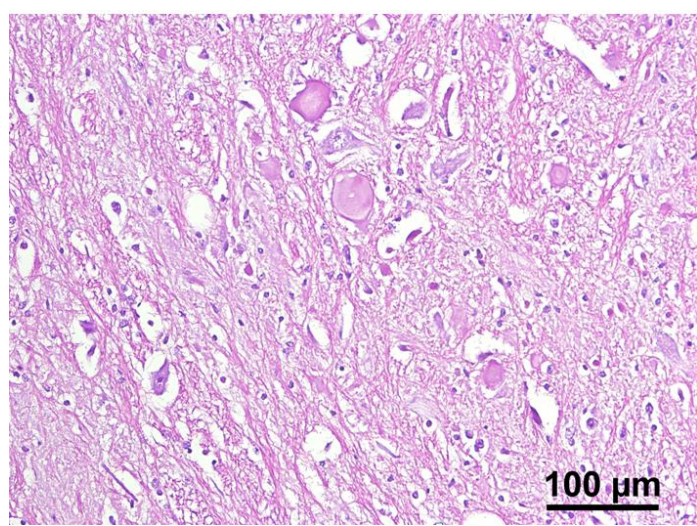

Figure 1. Histopathological photomicrograph of the central nervous system of mule (sterile hybrid equine species). Medulla oblongata, vacuolated, degenerated neurons with pale cytoplasm, dissociation of Nissl bodies, and oval or round, swollen axons with pale eosinophilic staining (axonal spheroids). Bar $(100 \mu \mathrm{m})$, objective (20x) and magnification (200x).

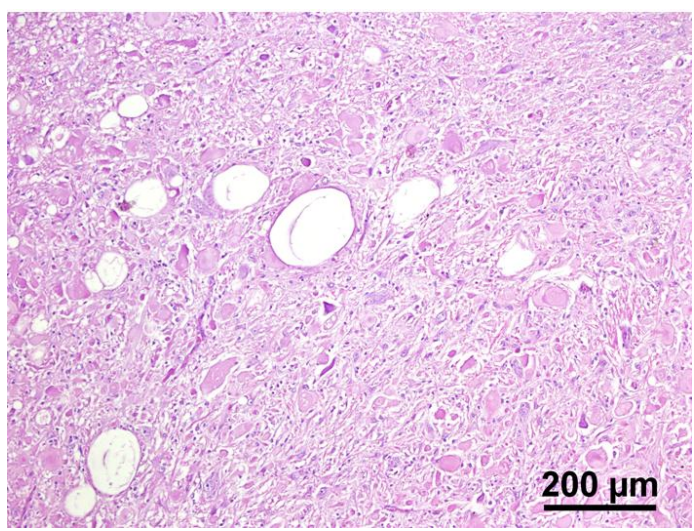

Figure 2. Histopathological photomicrograph of the central nervous system of mule (sterile hybrid equine species). Intense demyelination of medulla oblongata manifested as vacuolated areas (arrows), abundant axonal spheroid structures concomitant with degenerative neural process and microgliosis. Bar $(200 \mu \mathrm{m})$, objective (10x) and magnification (100x).

\section{DISCUSSION}

Clinical findings in the animal reported in this study, such as abnormal limb position, pelvic limb ataxia, thoracic limb hypermetria, spasticity and weakness were similar to those reported in previous studies with young horses presenting the same diagnosis (Mayhew et al., 1977; Beech and Haskins, 1987). Lesions in upper motor neuron and general proprioceptive system caused neurologic signs presented in this case report, confirming previous data (Mayhew et al., 1978). Similar to cases reported by Beech and Haskins (1987), there were no changes in CBC and serum biochemestry exams. No compression of the spinal cord was noticed in macroscopic postmortem examination, as published by Mayhew et al., (1978).

Histopathological findings were the same as the ones described by McGavin and Zachary (2007) for horses with NAD, including eosinophilic spheroids and mild degeneration in the brainstem and rare axonal spheroids in the spinal cord. These changes were similar to neuroaxonal dystrophy described in horses and to vitamin $\mathrm{E}$ deficiency ataxia in humans (Murphy and Mavis, 1981).

Mayhew et al. (1977) described dystrophic axons in different levels of the spinal cord, although more severe in the dorsal nucleus of the spinocerebellar tract, especially in the thoracic region (T10 to T15) These changes may confirm the initial clinical suspicion of the T3-L3 region as the lesion location. Neuro axonal degeneration was not confirmed in the sibling, nonetheless, clinical signs and disease progression reported by the owner may suggest a hereditary factor, such as previously described by Mayhew et al., (1978) and Finno (2012).

\section{CONCLUSION}

To our knowledge, this is the first clinical case of NAD in a mule. The clinical and histopathological characteristics are very similar to those reported for several equine breeds. Therefore, NAD should be considered as a diagnosis in mules presenting neurological changes. Reports like this are likely to provide novelty to existing knowledge on equine neuropathology and identification of new cases that may become more frequent or were left undiagnosed or even misdiagnosed, with special attention in mule medicine. 


\section{ACKNOWLEDGMENT}

Authors are thankful to Dr. Leonardo Meirelles from the Instituto Vital Brazil for his helpful assistance in sample collection.

\section{REFERENCES}

BAUMGÄRTNER, W.; FRESE, K.; ELMADFA, I. Neuroaxonal dystrophy associated with vitamin E deficiency in two Haflinger horses. J. Comp. Pathol., v.103, p.114-119, 1990.

BEECH, J.; HASKINS, M. Genetic studies of neuraxonal dystrophy in the Morgan. Am. J. Vet. Res., v.48, p.109-113, 1987.

FINNO, C.J.; HIGGINS, R.J.; ALEMAN, M. et al. Equine degenerative myeloencephalopathy in lusitano horses. J. Vet. Intern. Med., v.25, p.1439-1446, 2011.

FINNO, C.J. Clinical and genetic investigation of equine neuroaxonal dystrophy. 2012. Thesis (Doctoral PhD) - University of California, Davis, United States.
GORDON, N. Infantile neuroaxonal dystrophy (Seitelberger's disease). Dev. Med. Child Neurol., v.44, p.849-851, 2002.

MAYHEW, I.G.; DELAHUNTA, A.; WHITLOCK, R.H. et al. Equine degenerative myeloencephalopathy. J. Am. Vet. Med. Assoc., v.170, p.195-201, 1977.

MAYHEW, I.G.; DELAHUNTA, A.; WHITLOCK, R.H. et al. Spinal cord disease in the horse. Cornell Vet., v.68, Suppl.6, p.1-207, 1978.

McGAVIN M.D.; ZACHARY J.F. Pathologic basis of veterinary disease. 4.ed. St. Luis, Missouri: Mosby, 2007. 1476p.

MURPHY, D.J.; MAVIS, R.D. Membrane transfer of alpha-tocopherol. Influence of soluble alpha-tocopherol-binding factors from the liver, lung, heart, and brain of the rat. J. Biol. Chem., v.256, p.10464-10468, 1981.

REED, S.M. The neurological examination of the horse. In: NEW PERSPECTIVES IN EQUINE MEDICINE, 1998, Athens. Proceedings.... Athens: Center for Continuing Education, 1998. p.1-14. 